\title{
Pteridófitas usadas na legislação como indicadoras de estágios sucessionais no Estado de Santa Catarina, Brasil ${ }^{1}$
}

\author{
(D)Aline Possamai Della ${ }^{2,3}$ e Daniel de Barcellos Falkenberg ${ }^{2}$ \\ Recebido: 13 junho 2018; aceito: 28 junho 2019
}

Como citar: Della, A.P. \& Falkenberg, D.B. 2019. Pteridófitas usadas na legislação como indicadoras de estágios sucessionais no Estado de Santa Catarina, Brasil. Hoehnea 46: e572018. http://dx.doi.org/10.1590/2236-8906-57/2018.

\begin{abstract}
Pteridophytes used in legislation as indicators of successional stages in Santa Catarina State, Brazil). In the State of Santa Catarina, three resolutions of the Environment National Council (CONAMA) characterize the successional stages of plant formations for environmental licensing: 04/1994 (forests), 261/1999 (restinga), and 423/2010 (high altitude grasslands), showing indicator taxa, including pteridophytes. We evaluated the quality of indication of the 14 pteridophytes adopted as indicators of successional stages in these resolutions (six species in 261/1999, nine in 423/2010, and one in 04/1994) and discussed possible indicator species in six genera cited in 261/1999. We created two sets of criteria and, from Herbarium specimens and bibliographic review, applied these criteria to each evaluated species. We considered most species in resolution 261/1999 as a good indicator, as well as five other species (Lomariocycas schomburgkii, Neoblechnum brasiliense, Pleopeltis hirsutissima, Pleopeltis pleopeltifolia, and Serpocaulon latipes). On resolution 423/2010, only Lomariocycas schomburgkii and Pteridium esculentum were considered good indicators, being the last species also good for the early successional stage of forests. Revisions should be made in these resolutions in order to make them more appropriate, mainly incorporating more species to the resolution of forests.
\end{abstract}

Keywords: ecological indicators, ferns, forests, high altitude grasslands, restinga

RESUMO - (Pteridófitas usadas na legislação como indicadoras de estágios sucessionais no Estado de Santa Catarina, Brasil). No Estado de Santa Catarina, três resoluções do Conselho Nacional do Meio Ambiente (CONAMA) caracterizam estágios sucessionais de formações vegetacionais para licenciamento ambiental: 04/1994 (florestas), 261/1999 (restinga) e 423/2010 (campos de altitude), apresentando táxons indicadores, incluindo inclusive pteridófitas. Avaliamos a qualidade de indicação das 14 pteridófitas adotadas como indicadoras de estágios nessas resoluções (seis espécies na 261/1999, nove na 423/2010 e uma na 04/1994) e discutimos possíveis espécies indicadoras em seis gêneros citados na 261/1999. Criamos dois conjuntos de critérios e, a partir de coletas e revisão bibliográfica, aplicamos tais critérios a cada espécie avaliada. Consideramos a maioria das espécies na Resolução 261/1999 como boa indicadora, assim como cinco outras (Lomariocycas schomburgkii, Neoblechnum brasiliense, Pleopeltis hirsutissima, Pleopeltis pleopeltifolia e Serpocaulon latipes). Na Resolução 423/2010, apenas Lomariocycas schomburgkii e Pteridium esculentum foram julgadas boas indicadoras, a última também para estágio inicial das florestas. Revisões nessas resoluções poderão torná-las mais adequadas, principalmente incorporando mais espécies à Resolução das florestas.

Palavras-chave: campos de altitude, florestas, indicadores ecológicos, restinga, samambaias

\section{Introdução}

A legislação ambiental brasileira cresceu muito nos últimos anos, com o estabelecimento e a reformulação de normas, responsáveis por grandes mudanças na forma como vemos e utilizamos os recursos naturais. Essas alterações geram dúvidas quanto a possíveis avanços ou retrocessos em relação à conservação da Natureza. A comunidade científica, como parcela da sociedade que visa a compreender, discutir e buscar soluções para problemas ambientais, pouco avaliou (e avalia) a legislação sobre o meio ambiente, o que provavelmente se deve ao

1. Parte do Trabalho de Conclusão de Curso da primeira Autora

2. Universidade Federal de Santa Catarina, Centro de Ciências Biológicas, Departamento de Botânica, Rua Engenheiro Agronômico Andrei Cristian Ferreira, s/n, Trindade, Florianópolis, SC, Brasil

3. Autor para correspondência: alinepossamaidella@hotmail.com 
distanciamento entre as esferas política e científica (Turnhout et al. 2007). Isso justifica a necessidade de desenvolver estudos como este.

O Conselho Nacional do Meio Ambiente (Conama) é o órgão consultivo e deliberativo do Sistema Nacional do Meio Ambiente, que cria normas e critérios para o desenvolvimento da Política Nacional do Meio Ambiente (http://www.mma. gov.br/port/conama/estr.cfm). Entre tais normas estão resoluções que estabelecem parâmetros para caracterizar estágios sucessionais de formações vegetacionais. Essa caracterização é importante para o licenciamento ambiental, uma vez que baseia a análise da viabilidade da autorização de supressão da vegetação pelos órgãos ambientais. Sendo assim, essas resoluções acabam tendo grande relevância prática no cotidiano da população em geral e de muitos profissionais.

Para o Estado de Santa Catarina (SC) três resoluções podem ser citadas: a 04/1994 que estabelece os parâmetros para caracterizar os estágios sucessionais das florestas ombrófilas densa e mista e da estacional decidual, a 261/1999 para a restinga e a 423/2010 para os campos de altitude do sul do país. Essas normas caracterizam, por meio da estrutura e composição de espécies, a vegetação primária ou original e a vegetação secundária com os estágios inicial, médio e avançado de regeneração dessas formações. Somente para a restinga herbácea e/ou subarbustiva não houve a caracterização da vegetação secundária; nessa restinga são descritos três tipos de ambiente, mas sem reconhecer estágios sucessionais.

Dentre os aspectos da composição de táxons destacados nessas resoluções estão as espécies indicadoras, as quais refletem diretamente as características abióticas e bióticas dos estágios em cada formação e são componentes fundamentais dessas normas. Muitos táxons, de diferentes níveis taxonômicos, são usados como indicadores, pertencentes principalmente às angiospermas e pteridófitas. A análise do conjunto de indicadores e características ambientais é sempre necessária para se atingir a finalidade das resoluções, que é identificar estágios sucessionais em cada processo ou caso real, a fim de orientar os procedimentos de licenciamento ambiental. A resolução 261/1999 cita as principais espécies de cada estágio e ambiente, sem chamá-las de indicadoras, termo empregado nas outras resoluções; embora sejam conceitos distintos ("principais elementos da flora" $\mathrm{x}$ indicador), aqui tais espécies da 261/1999 serão tratadas, por simplicidade, igualmente como indicadoras, já que a expectativa era que cada conjunto de espécies mais importantes funcionasse como indicador para cada estágio ou ambiente. Neste artigo examinaremos apenas as pteridófitas, por ser um grupo mais facilmente analisável, ainda que menos valorizado na aplicação dessas normas.

Vários autores salientam o grande potencial das pteridófitas como indicador, pois são capazes de fornecer muitas informações sobre os ambientes que ocupam (como: integridade, fragmentação, poluição, etc.), já que sua distribuição tem grande correlação com variáveis abióticas como características do solo, umidade do ar e radiação solar, entre outras (Nóbrega et al. 2011), além de refletirem diretamente as mudanças dessas condições, causadas frequentemente por ações antrópicas. Muitas espécies são fortemente prejudicadas por tais alterações, mas outras, ao contrário, são adaptadas a perturbações e podem ser favorecidas por elas (Silva et al. 2018). Dessa forma, as pteridófitas podem ser usadas para indicar vários aspectos dos ambientes em que vivem, sendo úteis em análises da qualidade ambiental e de recuperação de áreas degradadas (Della 2016). Apesar desse potencial de indicação, elas ainda são pouco exploradas em normas que caracterizam estágios sucessionais de vegetações.

Assim, o objetivo deste estudo foi avaliar a qualidade de indicação das pteridófitas adotadas como indicadoras de estágios sucessionais de formação vegetacional, presentes nas resoluções do Conama (04/1994, 261/1999 e 423/2010) para o Estado de Santa Catarina, bem como apontar possíveis espécies indicadoras em seis gêneros mencionados na 261/1999 (dois com outras espécies incluídas na resolução e quatro sem espécie determinada nela).

\section{Métodos}

Foram criados dois conjuntos de critérios para a avaliação da qualidade de indicação dos táxons: um com aspectos gerais que definem um bom indicador e outro com características autoecológicas específicas para cada estágio sucessional. A partir do exame dos registros de coletas na rede SpeciesLink, das coletas e dos habitats preferenciais referidos na Flora Ilustrada Catarinense (FIC) (Sehnem 1968a, b, 1970a, b, 1972, 1974, 1978, 1979) e de estudos florísticos e/ou fitossociológicos em cada formação vegetacional, tais critérios foram aplicados a cada espécie avaliada.

Critérios de avaliação dos indicadores - O primeiro conjunto inclui critérios gerais, empregados na análise 
de todos os táxons independentemente da formação vegetacional, e julgou-se que a espécie não precisa atender a todos. Eles foram estabelecidos com base em revisão bibliográfica (Della 2016), sendo selecionados os mais lógicos e fáceis de serem usados.

Foi considerada boa indicadora a espécie que tenha ou seja:

- Cerca de no mínimo 50\% dos registros (da rede SpeciesLink e da FIC) no ambiente para o qual foi mencionada na resolução;

- Frequentemente citada nos trabalhos consultados sobre tal ambiente;

- Facilmente identificada em campo;

- Bastante visível e/ou destacada na natureza;

- Exclusiva do ambiente e/ou estágio sucessional para o qual foi apontada; se não exclusiva, que tenha uma distribuição com diferença significativa entre os ambientes e/ou estágios;

- Frequente e/ou abundante no ambiente para o qual foi proposta.

O segundo conjunto de critérios, que avalia a qualidade de indicação para os estágios sucessionais, é desigual entre as formações, devido às peculiaridades destas. Para as resoluções 04/1994 e 261/1999, que abordam vegetações em geral mais lenhosas, foi criado um conjunto, e outro foi empregado para a avaliação da resolução 423/2010, que trata de vegetação mais herbácea/campestre. Tais critérios também foram estabelecidos com base em revisão bibliográfica (Della 2016); para a resolução 423/2010 foi utilizada ainda a revisão de Andrade et al. (2015). Para os ambientes da resolução 261/1999 sem estágios (os três da restinga herbácea e/ou subarbustiva), não foi adotado esse segundo conjunto.

Para o estágio sucessional inicial das resoluções 04/1994 e 261/1999 avaliou-se:

- Capacidade de sobrevivência em ambientes alterados, em solos às vezes compactados;

- Tolerância à luminosidade intensa;

- Tolerância à redução de umidade (do solo e do ar);

- Tolerância à grande variação de temperatura;

- Crescimento rápido.

Para o estágio sucessional avançado das resoluções 04/1994 e 261/1999 considerou-se:

- Capacidade de sobrevivência em ambientes mais recuperados;

- Tolerância ao sombreamento;

- Tolerância ao aumento de umidade (do solo e do ar);

- Tolerância à menor variação de temperatura.

Para o estágio sucessional médio destas resoluções, as características não são facilmente definidas, tendo em vista que esse estágio apresenta aspectos tanto do inicial quanto do avançado, sendo difícil determinar quais seriam as características de suas espécies, supondo-se então que sejam intermediárias entre as condições consideradas anteriormente.

Para o estágio sucessional inicial da resolução 423/2010 avaliou-se:

- Capacidade de sobrevivência em ambientes alterados, que sofreram frequentes queimadas, intensa exploração por animais e/ou por atividades agrícolas.

Para os estágios sucessionais médio e avançado, e para a vegetação primária da mesma resolução, julgou-se:

- Capacidade de sobrevivência em ambientes mais recuperados, que não sofreram recentemente as alterações mencionadas para o estágio inicial.

Revisão de coletas da rede SpeciesLink - Para cada espécie citada nas resoluções foram realizadas buscas na rede SpeciesLink (http://www.splink.org. br/; fevereiro a novembro de 2016), empregando como filtros o nome da espécie (e seus sinônimos), a formação vegetacional (restinga; duna; campo de altitude; floresta pluvial atlântica; floresta com araucária; floresta da bacia do rio Uruguai; floresta ombrófila densa; floresta ombrófila mista; floresta estacional decidual - e ainda usando o termo mata ao invés de floresta nos seis últimos itens) para a qual foi adotada como indicadora, e o Estado (SC), a fim de se obter o número total de coletas da espécie em cada ambiente. Para a resolução 423/2010 foram feitas buscas também com PR e RS como estado, uma vez que a norma é para todo o sul do país. Estas coletas tiveram suas informações ambientais interpretadas para a avaliação das características autoecológicas das espécies.

Revisão bibliográfica - Para cada táxon presente nestas resoluções foi realizada uma revisão bibliográfica, em que se buscaram informações ecológicas gerais da espécie, como habitat, condição de solo, preferências quanto a sombreamento, umidade, etc, e informações específicas dela em cada formação vegetacional em que foi tratada como indicadora, entre elas: ambiente e/ou tipo de vegetação em que ocorre, e sua frequência e abundância nestes. Para essa revisão, executaram-se buscas no Google (acadêmico ou não) com as seguintes palavras chave: nome da espécie (e seus sinônimos) e a formação vegetacional. Além disso, foi consultada a FIC, na qual tanto as coletas mencionadas como as observações ecológicas foram interpretadas para a avaliação das características autoecológicas das espécies. 
Para a restinga, 18 trabalhos foram selecionados a partir dessas buscas (ver tabela 2 a seguir). Para os campos de altitude, seis estudos foram considerados (Mocochinski 2006, Simão 2008, Gomes 2009, Zanin et al. 2009, Magalhães et al. 2013, Campestrini 2014). E para as florestas, quatro trabalhos (Tabarelli \& Mantovani 1999, Mauhs 2002, Sampaio \& Guarino 2007, Maraschin-Silva et al. 2009).

Seleção e avaliação de outras possíveis espécies indicadoras na restinga - A resolução 261/1999 citou ainda Blechnum spp., Gleichenia spp., Lycopodium spp., Microgramma spp., Polypodium spp. e Salvinia spp. Estes seis gêneros foram incluídos nela por possuírem espécies importantes (mas cuja diferenciação não seria relevante) ou para indicar a ocorrência de outras espécies dele (menos conhecidas ou cuja menção não acrescentaria informação significativa) além da já nomeada naquele ponto específico. Nesses casos, para auxiliar a futura revisão da norma, buscouse apontar possíveis espécies indicadoras, sendo selecionadas as com maior quantidade de coletas na restinga de Santa Catarina que ainda não constassem na resolução. Para essa seleção, realizaram-se buscas na rede SpeciesLink (fevereiro a novembro de 2016), empregando como filtros os nomes dos gêneros, o ambiente (restinga ou dunas) e o Estado (SC). A seguir, as espécies selecionadas foram avaliadas (como todas as demais das resoluções) quanto aos conjuntos de critérios, mediante revisões bibliográficas e de coletas (cf. seções anteriores).

Restinga - Resolução do Conama 261/1999 - Nessa resolução foram usadas como indicadores seis espécies identificadas em nível específico e seis grupos (gêneros) de espécies não identificadas neste nível, mais uma que foi tratada como endêmica ou rara ou ameaçada de extinção (tabela 1).

Revisão bibliográfica dos táxons adotados como indicadores - Na tabela 2 verifica-se a vegetação ou o ambiente no qual cada espécie indicadora (resolução 261/1999) ou potencialmente indicadora (cf. Métodos) foi apontada nos 18 estudos revisados. As três espécies com mais citações foram Telmatoblechnum serrulatum (Rich.) Perrie, D.J. Ohlsen \& Brownsey, Rumohra adiantiformis (G. Forst.) Ching e Microgramma vacciniifolia (Langsd. \& Fisch.) Copel., que podem ser consideradas as principais pteridófitas da restinga brasileira, por suas amplas ocorrência e distribuição geográfica nesta formação.
Análise das espécies indicadoras - Das seis identificadas e apontadas como indicadoras, três chamam a atenção pela grande amplitude de ambientes e estágios sucessionais para os quais são referidas: Telmatoblechnum serrulatum (como Blechnum serrulatum Rich. na resolução, onde poderia também ser inserida na restinga herbácea e/ou subarbustiva e na restinga arbórea primária e em estágios médio e avançado, com base na Tabela 2 e obs. pess.), Pleopeltis lepidopteris (Langsd. \& Fisch.) de la Sota (como Polypodium lepidopteris (Langsd. \& Fisch.) Kunze) e Rumohra adiantiformis (é incompreensível sua exclusão na restinga arbórea em estágios médio e avançado). Apesar de essas espécies serem facilmente identificadas, terem grande visibilidade e serem frequentes e abundantes na restinga, a grande amplitude de ocorrência delas nessa formação reduz seu potencial para identificar e principalmente diferenciar os habitats nos quais foram citadas na resolução. Assim, é importante verificar em que tipo de restinga cada uma é mais abundante, para posteriormente definir onde elas seriam melhores indicadoras. Se elas forem mais abundantes em uma vegetação que nas demais, poderão ser consideradas boas indicadoras; se este não for o caso, sua utilidade como indicadoras estaria comprometida, embora elas sejam realmente elementos importantes da flora da restinga, como dito nesta resolução.

Vale a pena ressaltar que, por mais que estas plantas sejam características da restinga, as mesmas acabam não sendo tão úteis isoladamente para a caracterização e distinção dos estágios sucessionais, pela grande variedade de ambientes em que ocorrem. Além disso, para a seleção de táxons indicadores, deve-se buscar espécies exclusivas de um estágio (ou amplamente preferenciais dele), as quais seriam mais informativas e mais facilmente empregadas numa análise.

Acrostichum danaeifolium Langsd. \& Fisch. e Pteridium esculentum (G. Forst.) Cockayne subsp. arachnoideum (Kaulf.) Thomson (tratada como $P$. aquilinum (L.) Kuhn) atendem grande parte dos critérios gerais (são facilmente reconhecíveis, têm grande visibilidade e quantidade razoável de coletas e estudos mencionando-as para a restinga) adotados para uma boa espécie indicadora. P. esculentum subsp. arachnoideum também cumpre todos os critérios aqui assumidos para o estágio inicial. Ambas têm ocorrência mais restrita e são boas indicadoras dos estágios sucessionais e/ou ambientes para os quais foram citadas na resolução. 
Tabela 1. Pteridófitas indicadoras dos ambientes e/ou dos estágios sucessionais da Restinga do Estado de Santa Catarina,de SC segundo a resolução do Conama 261/1999. PDF: praia e dunas frontais. DIP: dunas internas e planícies. LBB: lagunas, banhados e baixadas. Estágios - PRI: primária. INI: inicial. MÉD: médio. AVA: avançado. *. Com * a espécie considerada endêmica ou rara ou ameaçada de extinção.

Table 1. Pteridophytes indicating environments and/or successional stages of restinga of SC, according to Conama resolution 261/1999. PDF: beach and front dunes. DIP: internal dunes and plains. LBB: ponds, wetland and lowlands. Stages - PRI: primary. INI: initial. MED: medium. AVA: advanced. With * the species considered endemic or rare or endangered.

\begin{tabular}{|c|c|c|c|c|c|c|c|c|c|c|c|}
\hline \multirow[t]{2}{*}{ Táxons } & \multicolumn{3}{|c|}{$\begin{array}{l}\text { Restinga herbácea e/ou } \\
\text { subarbustiva }\end{array}$} & \multicolumn{4}{|c|}{ Restinga arbustiva } & \multicolumn{4}{|c|}{ Restinga arbórea } \\
\hline & PDF & DIP & LBB & PRI & INI & MÉD & AVA & PRI & INI & MÉD & AVA \\
\hline Acrostichum danaeifolium & & & $\mathrm{X}$ & & & & & & & & \\
\hline Blechnum serrulatum & & & & $\mathrm{X}$ & & $\mathrm{X}$ & $\mathrm{X}$ & & & & \\
\hline Blechnum spp. & & & & & & & & $\mathrm{X}$ & & & $\mathrm{X}$ \\
\hline Gleichenia spp. & & & & & & & & & $\mathrm{X}$ & & \\
\hline Lycopodium spp. & & & $\mathrm{X}$ & & & & & & & & \\
\hline Microgramma spp. & & & & $\mathrm{X}$ & & & & & & & \\
\hline Polypodium lepidopteris & $\mathrm{X}$ & $\mathrm{X}$ & & $\mathrm{X}$ & & $\mathrm{X}$ & $\mathrm{X}$ & & & & \\
\hline Polypodium robustum & & & & & & & & $\mathrm{X}$ & & & $\mathrm{X}$ \\
\hline Polypodium spp. & & & & & & & & $\mathrm{X}$ & & $\mathrm{X}$ & $\mathrm{X}$ \\
\hline Pteridium aquilinum & & & & & $\mathrm{X}$ & & & & $\mathrm{X}$ & & \\
\hline *Regnellidium diphyllum & & & $\mathrm{X}$ & & & & & & & & \\
\hline Rumohra adiantiformis & $\mathrm{X}$ & $\mathrm{X}$ & & $\mathrm{X}$ & & $\mathrm{X}$ & $\mathrm{X}$ & $\mathrm{X}$ & & & \\
\hline Salvinia spp. & & & $\mathrm{X}$ & & & & & & & & \\
\hline
\end{tabular}

Pecluma robusta (Fée) M. Kessler \& A.R. Sm. (tratada como Polypodium robustum Fée) não parece tão frequente e abundante nos ambientes para os quais foi apontada, mas é abundante em vários pontos deles; não é facilmente identificada, por ser similar a Pecluma paradiseae (Langsd. \& Fisch.) M.G. Price. Há escassez de informações sobre a espécie que, no entanto, apresenta características aqui estabelecidas para estágio avançado e/ou de vegetação primária (obs. pess.). Assim, apesar de algumas dificuldades, pode ser razoável indicadora de tais estágios de restinga arbórea.

Regnellidium diphyllum Lindm. foi referida na resolução como endêmica ou rara ou ameaçada de extinção, ocorrente na vegetação de lagunas, banhados e baixadas da restinga herbácea e/ou subarbustiva, o que é correto com base nas poucas coletas e na bibliografia disponíveis, embora seja exclusiva do extremo sul de SC.

Análise dos gêneros citados sem determinar espécies A partir das buscas realizadas na rede SpeciesLink, 18 outras espécies foram selecionadas e incorporadas na análise destes gêneros. Outras três (Telmatoblechnum serrulatum, Pleopeltis lepidopteris e Pecluma robusta), potencialmente incluídas no termo "spp." a seguir, já foram examinadas na seção anterior.

a) Blechnum spp.

Três outras espécies foram analisadas: Blechnum occidentale L., Lomariocycas schomburgkii (Klotzsch) Gasper \& A.R. Sm. e Neoblechnum brasiliense (Desv.) Gasper \& V.A.O. Dittrich, as duas últimas recentemente transferidas de Blechnum. Apenas $N$. brasiliense parece ser boa indicadora dos estágios médio e avançado da restinga arbórea, pois apresenta a maioria das características pré-estabelecidas para estágios mais conservados (tolera sombreamento, ambientes recuperados e aumento de umidade), bem como atende parte dos critérios gerais de um bom indicador (é facilmente identificada e visualizada). Essa espécie ainda é frequente em vegetação de lagunas, banhados e baixadas e na vegetação de dunas internas e planícies da restinga herbácea e/ ou subarbustiva. $N$. brasiliense poderia ser boa indicadora para todos esses ambientes; no entanto, seria importante estabelecer em qual é mais abundante e para qual seria melhor indicadora. 


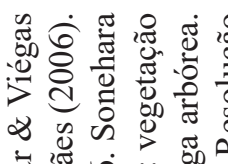

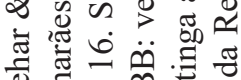

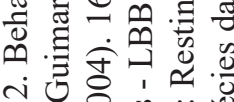

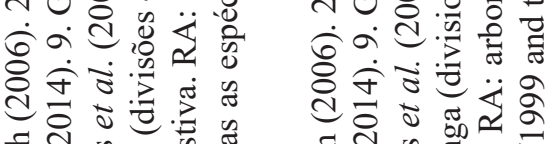

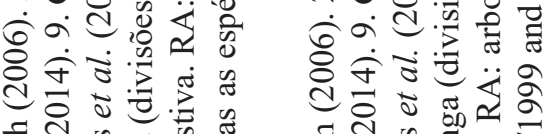

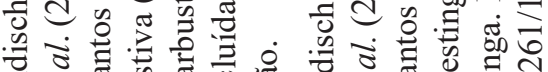

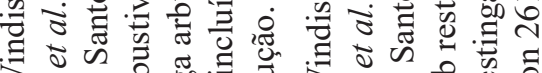

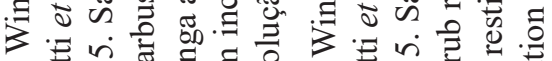

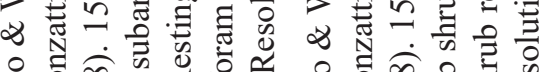

¿ $0 \dot{0}$ क

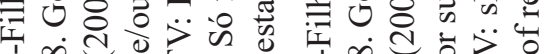

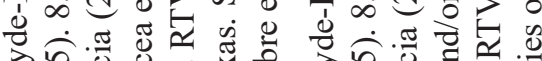

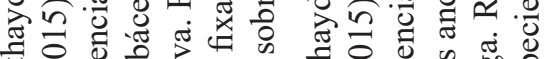

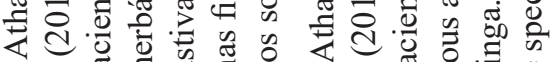

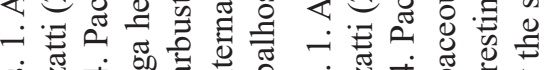

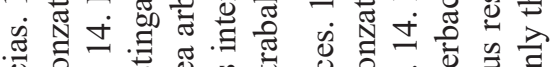

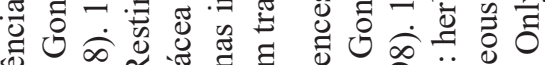

耐

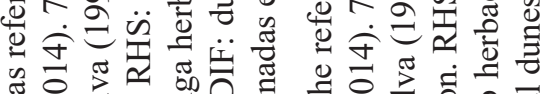

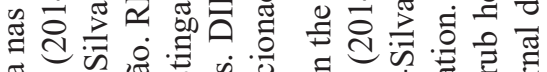

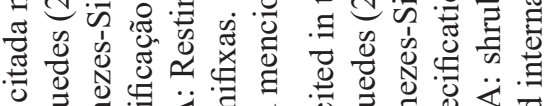

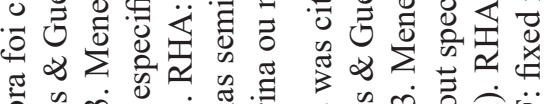

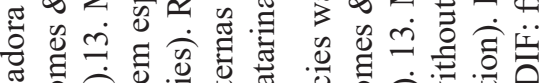

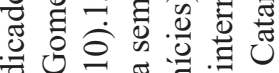

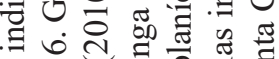

(0)

훌

क 0.0

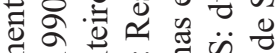

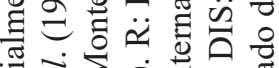

응워

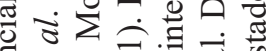

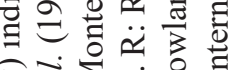

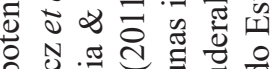

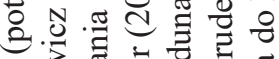

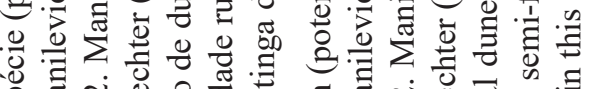

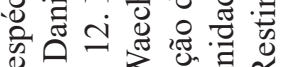

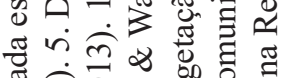

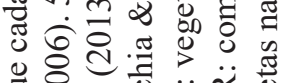

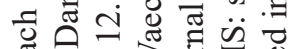
웡.

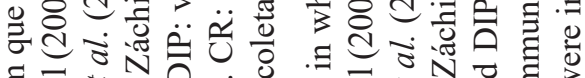

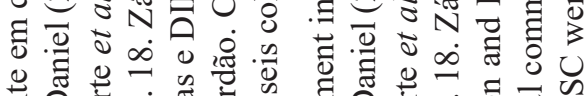

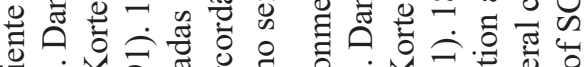
产

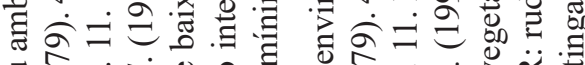

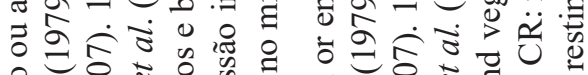

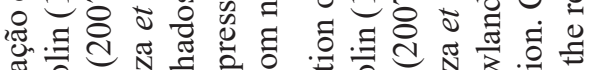

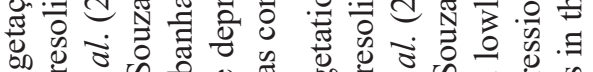

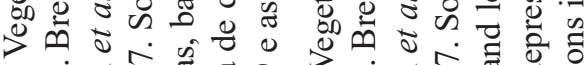
i่

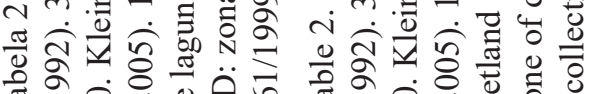

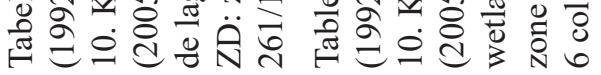

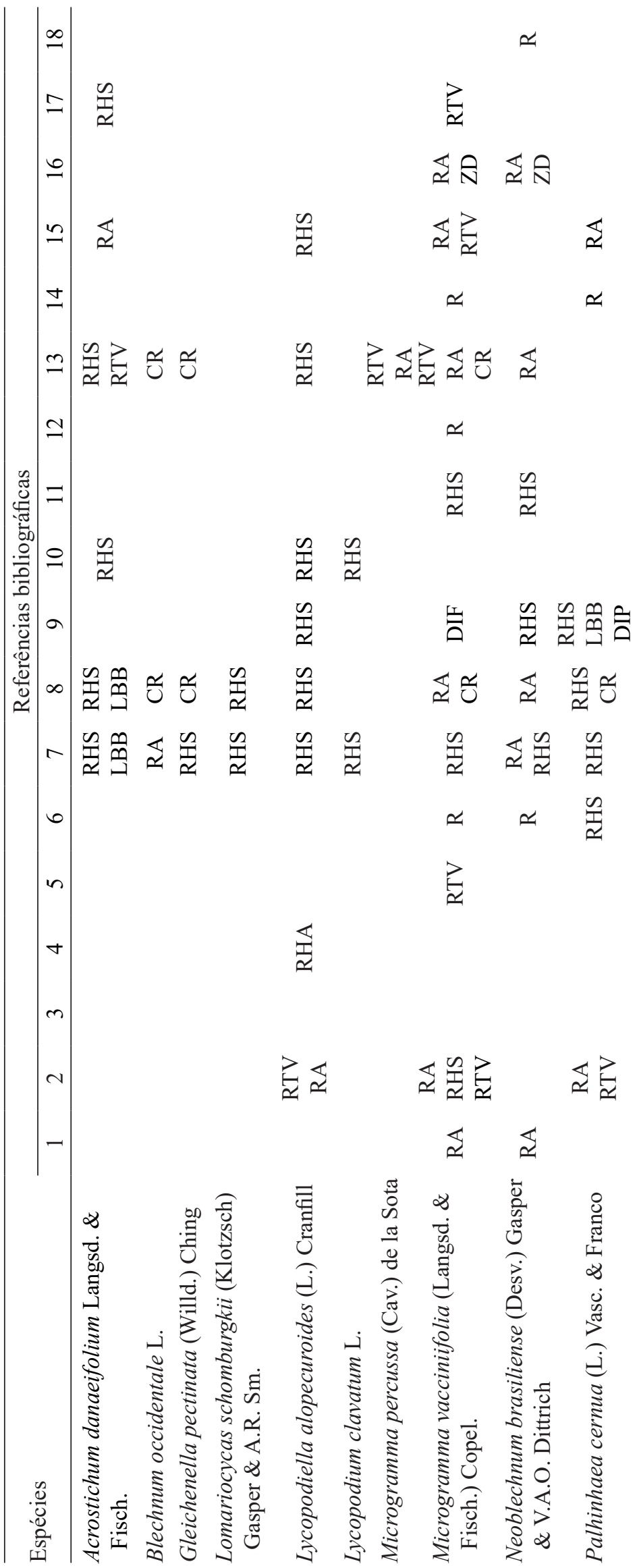




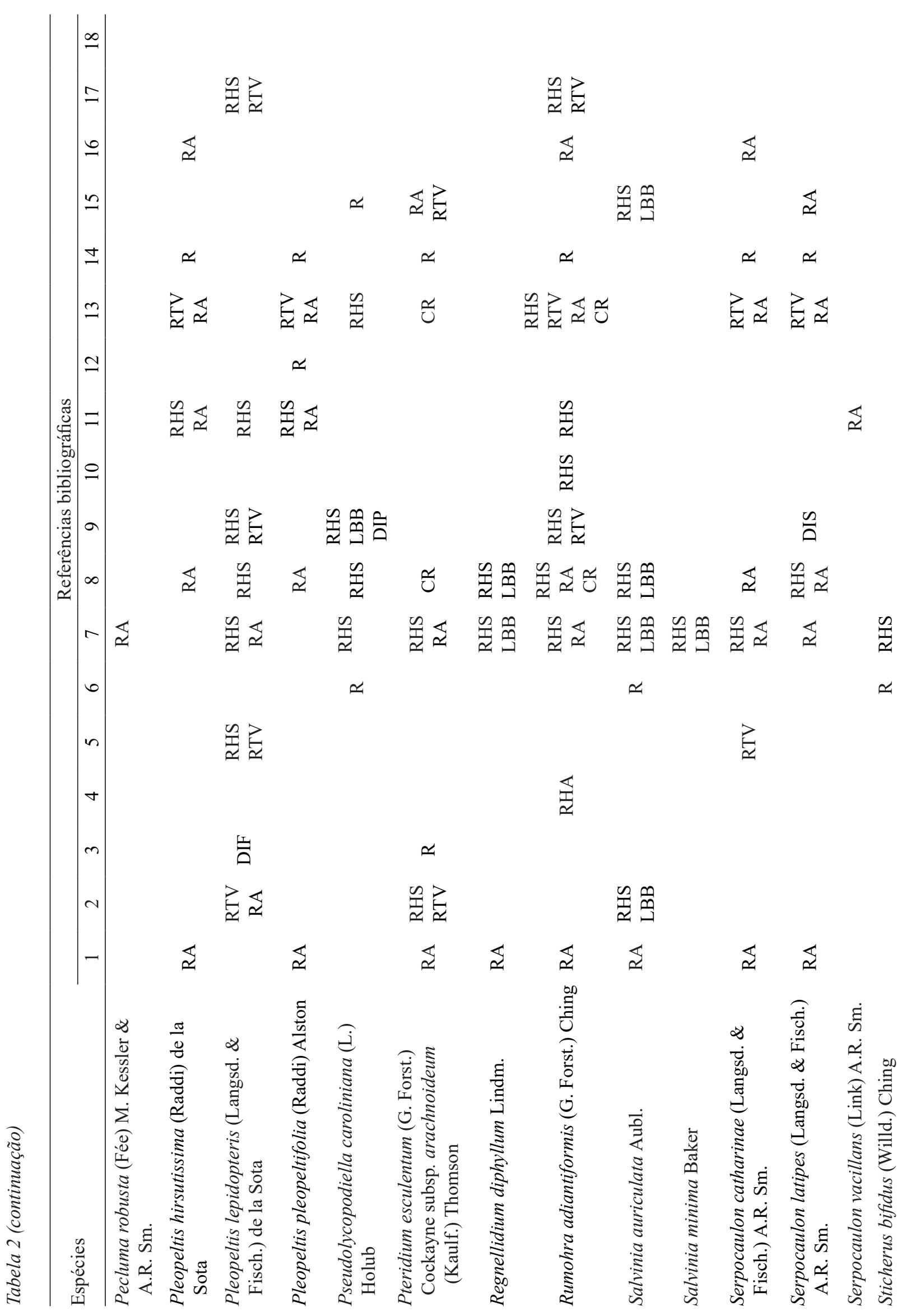


B. occidentale não parece boa indicadora, pois há poucas coletas e obras que mostrem sua ocorrência na restinga. Além disso, há carência de informações autoecológicas, o que dificulta a análise do seu potencial como indicadora de estágios sucessionais.

L. schomburgkii, apesar de ter poucas coletas e referências bibliográficas na restinga, pode ser abundante na restinga herbácea e/ou subarbustiva na metade sul de SC (obs. pess.), o que demonstra seu potencial como indicadora da vegetação de banhados e baixadas.

\section{b) Gleichenia spp.}

Três espécies foram analisadas: Gleichenella pectinata (Willd.) Ching, Sticherus bifidus (Willd.) Ching e S. nigropaleaceus (Sturm) J. Prado \& Lellinger. Cada uma tinha apenas um registro explícito na restinga do sul do Brasil, todos de Santa Catarina. Foram citadas em apenas quatro trabalhos, em geral para ambientes diferentes do que ocupariam segundo a resolução. Por isso, essas espécies não foram aqui consideradas boas indicadoras de estágio inicial de restinga arbórea, embora eventualmente ocorram em estágios iniciais da restinga. Porém, seus gêneros ou a família Gleicheniaceae podem ser indicadores razoáveis, visto que praticamente não aparecem em estágios médio ou avançado na restinga; assim, a inclusão desses táxons supraespecíficos no estágio inicial é lógica e aceitável, pois é uma possível diferença em relação aos demais estágios e exemplifica um caso de o nível de espécie ser desnecessário para certos objetivos de indicação.

\section{c) Lycopodium spp.}

Três espécies foram analisadas: Lycopodiella alopecuroides (L.) Cranfill, Palhinhaea cernua (L.) Vasc. \& Franco e Pseudolycopodiella caroliniana (L.) Holub, por terem sido identificadas em coletas na restinga de SC. Há poucas referências citando-as para a restinga. Palhinhaea cernua tem também poucas coletas inequívocas da restinga, mas é abundante perto da sede da Estação Ecológica de Carijós (obs. pess.). Após nossa análise (Della 2016), Øllgaard \& Windisch (2016) mostraram que Lycopodiella alopecuroides e Pseudolycopodiella caroliniana são limitadas ao hemisfério norte (América do Norte e Cuba), e reconheceram Lycopodiella tupiana (B. Øllg. \& P.G. Windisch) B. Øllg., Pseudolycopodiella meridionalis (Underw. \& Lloyd) Holub e algumas outras espécies na restinga de $\mathrm{SC}$ como as plantas que em geral eram tratadas como Lycopodiella alopecuroides e 
P. caroliniana. Essa nova conceituação ainda está pouco adotada em obras e coletas, dificultando a reanálise dos dados. Há pelo menos duas espécies características e frequentes em vegetação de baixadas úmidas de restinga herbácea e/ou subarbustiva (obs. pess.), que julgamos como razoáveis indicadoras desta, mesmo que as informações levantadas ainda sejam insuficientes.

d) Microgramma spp.

Duas espécies foram analisadas: $M$. percussa (Cav.) de la Sota e M. vacciniifolia (Langsd. \& Fisch.) Copel. A primeira não foi considerada boa indicadora, pois poucas coletas e publicações a citam para restinga. $M$. vacciniifolia, no entanto, tem quantidade razoável de trabalhos apontando-a para restinga arbustiva, além de possuir a maioria das características aqui estabelecidas para a vegetação primária e para o estágio avançado, e a maioria das características gerais de uma boa espécie indicadora. Essa espécie também ocorre em restinga arbórea primária e em estágio avançado, e na restinga herbácea e/ou subarbustiva; é necessário avaliar onde tal espécie é mais abundante e onde seria melhor indicadora.

e) Polypodium spp.

Cinco outras espécies foram analisadas: Pleopeltis hirsutissima (Raddi) de la Sota, Pleopeltis pleopeltifolia (Raddi) Alston, Serpocaulon catharinae (Langsd. \& Fisch.) A.R. Sm., Serpocaulon latipes (Langsd. \& Fisch.) A.R. Sm. e Serpocaulon vacillans (Link) A.R. Sm.

Três (P. hirsutissima, P. pleopeltifolia e $S$. latipes) foram consideradas boas indicadoras da restinga arbórea primária e em estágio avançado, e as duas primeiras também do médio. Elas apresentam a maioria das características gerais de um indicador (facilmente visualizadas, quantidade razoável de coletas e trabalhos citando-as para a restinga) e a maioria das características aqui estabelecidas para o estágio avançado (toleram sombreamento, ambientes recuperados e aumento de umidade). $S$. catharinae necessita de novas análises para se obter um resultado mais conclusivo a respeito do seu potencial de indicação, pois tem muito poucas coletas na restinga, bem como parece não ser frequente e abundante na restinga arbórea. Já $S$. vacillans não foi julgada boa indicadora, porque há pouquíssimas coletas e obras mencionando-a para Santa Catarina; com essa escassez de informações, é difícil determinar se ela apresenta ou não as características de um indicador de estágio avançado e vegetação primária. f) Salvinia spp.

Duas espécies foram analisadas: $S$. auriculata Aubl. e S. minima Baker. Apesar da dificuldade de identificação, em função das semelhanças morfológicas entre elas, há quantidade razoável de coletas e trabalhos citando-as para vegetação de lagunas, banhados e baixadas de restinga herbácea e/ ou subarbustiva. Assim, pode-se concluir que o gênero Salvinia seja um bom indicador para este tipo de ambiente, embora cada espécie individualmente não. É outro exemplo de caso em que o nível de espécie é inútil para o objetivo de indicação.

Como visto, poucas espécies de pteridófitas foram incluídas nessa resolução, comparando-se com as mais de duas centenas de angiospermas que a integram, o que determina uma importância secundária das primeiras. Porém, várias pteridófitas têm grande potencial de indicação, como verificado aqui, justificando sua presença na norma. Além disso, algumas outras espécies aqui analisadas se mostraram boas indicadoras, demonstrando, portanto, que poderiam ser adicionadas numa nova versão dessa resolução (tabela 3).

Campos de altitude - Resolução do Conama 423/2010 - Nessa resolução foram adotadas nove espécies de pteridófitas como indicadoras (tabela 4).

Apenas Lomariocycas schomburgkii (tratada como Blechnum imperiale (Fée \& Glaz.) Christ na resolução) e Pteridium esculentum subsp. arachnoideum (como P. aquilinum var. arachnoideum (Kaulf.) Brade) foram consideradas boas indicadoras, L. schomburgkii de vegetação primária e dos estágios médio e avançado, e $P$. esculentum subsp. arachnoideum de estágio inicial. Ambas apresentam a maioria das características de um bom indicador (facilmente reconhecíveis, bastante visíveis e/ou destacadas em seu habitat, frequentes e abundantes nessa formação). L. schomburgkii tem todas as características aqui estabelecidas para estágios mais conservados, ao passo que $P$. esculentum subsp. arachnoideum apresenta todas as características aqui previstas para o estágio inicial de regeneração.

Diphasiastrum thyoides (Willd.) Holub (Lycopodiella thyoides foi o nome usado na resolução; supomos que os autores da resolução quisessem se referir a Lycopodium thyoides Humb. \& Bonpl. ex Willd., mas não encontramos a combinação dessa espécie para Lycopodiella), Parablechnum cordatum (Desv.) Gasper \& Salino (tratada como Blechnum regnellianum (Kunze) C. Chr.) e Selaginella 
Tabela 3. Pteridófitas indicadoras dos ambientes e/ou dos estágios sucessionais da Restinga do Estado de Santa Catarinade SC, com atualizações nomenclaturais e novas sugestões (+) para revisar a resolução do Conama 261/1999. PDF: praia e dunas frontais. DIP: dunas internas e planícies. LBB: lagunas, banhados e baixadas. Estágios - PRI: primária. INI: inicial. MÉD: médio. AVA: avançado. *Com * a espécie considerada endêmica ou rara ou ameaçada de extinção. X: menção na resolução. +: inclusão aqui sugerida. ?: possibilidade a ser melhor examinada.

Table 3. Pteridophytes indicating environments and/or successional stages of restinga of SC, with nomenclatural updates and new suggestions $(+)$ to revise Conama resolution 261/1999. PDF: beach and front dunes. DIP: internal dunes and plains. LBB: ponds, wetland and lowlands. Stages - PRI: primary. INI: initial. MED: medium. AVA: advanced. With * the species considered endemic or rare or endangered. X: mentioned in resolution, +: inclusion suggested here,?: Possibility to be further examined.

\begin{tabular}{|c|c|c|c|c|c|c|c|c|c|c|c|}
\hline \multirow[t]{2}{*}{ Táxons } & \multicolumn{3}{|c|}{$\begin{array}{c}\text { Restinga herbácea e/ } \\
\text { ou subarbustiva }\end{array}$} & \multicolumn{4}{|c|}{ Restinga arbustiva } & \multicolumn{4}{|c|}{ Restinga arbórea } \\
\hline & PDF & DIP & LBB & PRI & INI & MÉD & AVA & PRI & INI & MÉD & AVA \\
\hline Acrostichum danaeifolium & & & $\mathrm{X}$ & & & & & & & & \\
\hline Gleicheniaceae & & & & & $?$ & & & & $\mathrm{X}$ & & \\
\hline Lomariocycas schomburgkii & & & + & & & & & & & & \\
\hline Lycopodiella tupiana & & & + & & & & & & & & \\
\hline Microgramma vacciniifolia & & + & & + & & & + & + & & & + \\
\hline Neoblechnum brasiliense & & + & + & & & & & & & + & + \\
\hline Palhinhaea cernua & & & $?$ & & & & & & & & \\
\hline Pecluma robusta & & & & & & & & $\mathrm{X}$ & & & $\mathrm{X}$ \\
\hline Pleopeltis hirsutissima & & & & & & & & + & & + & + \\
\hline Pleopeltis lepidopteris & $\mathrm{X}$ & $\mathrm{X}$ & & $\mathrm{X}$ & & $\mathrm{X}$ & $\mathrm{X}$ & & & & \\
\hline Pleopeltis pleopeltifolia & & & & & & & & + & & + & + \\
\hline $\begin{array}{l}\text { Pseudolycopodiella } \\
\text { meridionalis }\end{array}$ & & & $?$ & & & & & & & & \\
\hline $\begin{array}{l}\text { Pteridium esculentum subsp. } \\
\text { Arachnoideum }\end{array}$ & & & & & $\mathrm{X}$ & & & & $\mathrm{X}$ & & \\
\hline *Regnellidium diphyllum & & & $\mathrm{X}$ & & & & & & & & \\
\hline Rumohra adiantiformis & $\mathrm{X}$ & $\mathrm{X}$ & & $\mathrm{X}$ & & $\mathrm{X}$ & $\mathrm{X}$ & $\mathrm{X}$ & & + & + \\
\hline Salvinia & & & $\mathrm{X}$ & & & & & & & & \\
\hline Serpocaulon latipes & & & & & & & & + & & & + \\
\hline Telmatoblechnum serrulatum & & + & + & $\mathrm{X}$ & & $\mathrm{X}$ & $\mathrm{X}$ & + & & + & + \\
\hline
\end{tabular}

microphylla (Kunth) Spring necessitam de novas análises para um resultado mais conclusivo acerca do seu potencial indicador para a vegetação primária e para os estágios médio e avançado dos campos de altitude. Foram pouco coletadas nesses campos, mas atendem alguns dos critérios gerais assumidos para um bom indicador (facilmente reconhecíveis e visíveis e/ ou destacadas em seu habitat, embora a última tenha porte reduzido) e parecem sobreviver em ambientes recuperados ou conservados.

Lycopodiella alopecuroides e Pseudolycopodiella caroliniana (esta como Lycopodiella na resolução) também devem ser revistas, pois, como comentado anteriormente, não ocorrem no Brasil (Øllgaard \& Windisch 2016).Além disso, havia relativamente poucas coletas e referências dessas espécies explicitamente de ambientes campestres. Lycopodiella geometra B. Øllg. \& P.G. Windisch, Lycopodiella longipes (Grev. \& Hooker) Holub, Pseudolycopodiella carnosa (Silveira) Holub e $P$. meridionalis, reconhecidas por Øllgaard \& Windisch (2016) e identificadas antes com os nomes que iniciam este parágrafo, sobrevivem nos ambientes recuperados e especialmente nos mais conservados e úmidos, mas ainda não estão muito adotadas em coletas e principalmente obras. Portanto, é necessária uma ampla reanálise das espécies de 
Tabela 4. Pteridófitas indicadoras de estágios sucessionais nos Campos de Altitude no sul do Brasil, segundo a resolução do Conama 423/2010.

Table 4. Pteridophytes indicating successional stages of high altitude grasslands in southern Brazil according to Conama Resolution 423/2010.

\begin{tabular}{lcc}
\hline Táxons & Estágio inicial & $\begin{array}{r}\text { Vegetação primária e estágios médio } \\
\text { e avançado }\end{array}$ \\
\hline Blechnum imperiale & & $\mathrm{X}$ \\
Blechnum regnellianum & & $\mathrm{X}$ \\
Gleichenella pectinata & & $\mathrm{X}$ \\
Gleichenia brasiliensis & & $\mathrm{X}$ \\
Lycopodiella alopecuroides & & $\mathrm{X}$ \\
Lycopodiella carolinianum & $\mathrm{X}$ \\
Lycopodiella thyoides & $\mathrm{X}$ & $\mathrm{X}$ \\
Pteridium aquilinum var. arachnoideum & & \\
Selaginella microphylla & & \\
\hline
\end{tabular}

Lycopodiaceae que deverão figurar numa próxima versão desta resolução.

Gleichenella pectinata (Willd.) Ching não é considerada boa indicadora da vegetação primária e dos estágios médio e avançado dos campos de altitude. Não há registros de coletas ou publicações que a mencionem para esse ambiente, mostrando que não é frequente e abundante nesses campos, assim como em geral não sobrevive em ambientes mais recuperados; ao contrário, é mais frequente em ambientes alterados (Sehnem 1970a).

Gleichenia brasiliensis foi citada pela resolução, mas não foi encontrada na Lista da Flora do Brasil e no Tropicos. Esse nome também não foi localizado na bibliografia analisada, por isso não foi discutido aqui. Há uma espécie cujo epíteto específico se assemelha e que pode ter sido confundida na elaboração da resolução: G. brasiliana (Desv.) Spreng., apontada como sinônimo de G. pectinata no Herbário do Jardim Botânico de Edimburgo, num suposto tipo de $G$. brasiliana.

$\mathrm{Na}$ resolução dos campos as pteridófitas têm igualmente uma importância secundária, diante das várias centenas de angiospermas ali incluídas. Poucas foram as espécies aqui julgadas como boas indicadoras; além disso, há vários problemas taxonômicos com as espécies adotadas, o que determina a necessidade de uma ampla revisão dessa parte da norma.

Mata Atlântica - Resolução do Conama 04/1994 Nessa resolução, P. esculentum subsp. arachnoideum (tratada como $P$. aquilinum) foi a única pteridófita usada como indicadora, referida para o estágio inicial de regeneração das florestas ombrófilas densa e mista e da estacional decidual. É uma boa indicadora, pois apresenta quantidade razoável de registros para matas (apesar de não ter qualquer registro explícito para a floresta estacional decidual de Santa Catarina) e muitos trabalhos a mencionam para ambientes florestais, bem como apresenta a maioria das características gerais de um bom indicador e atende a todos os critérios aqui assumidos para o estágio inicial de regeneração.

Essa resolução apresentou poucas espécies indicadoras, mesmo de plantas com semente. Os parâmetros numéricos (diâmetro, área basal e altura) também presentes nela acabam sendo mais valorizados na sua aplicação prática que as espécies, o que é um erro frequentemente aceito pelos órgãos de licenciamento ambiental, em parte justificado pela insuficiência de espécies indicadoras. Apenas uma pteridófita como indicadora é um número insignificante diante das mais de quatro centenas de espécies deste grupo existentes nessas formações (Gasper \& Salino 2015), nas quais muitos táxons possuem grande potencial de indicação (Della 2016). Uma futura revisão dessa resolução deverá incorporar novos táxons.

Visão geral das três resoluções - As resoluções aqui analisadas incluíram um total de 14 espécies identificadas de pteridófitas como indicadoras. A resolução 261/1999 apresentou a maior quantidade (seis espécies, mais seis grupos de espécies não identificadas), seguida pela resolução 423/2010 (nove espécies) e pela resolução 04/1994 (uma espécie), o que é uma incoerência, dadas as elevadas riqueza e diversidade das pteridófitas florestais, e a suposta importância reduzida das pteridófitas em campos de altitude. Talvez por ser mais antiga, a norma com 
táxons indicadores dos estágios sucessionais das florestas ombrófilas densa e mista e da estacional decidual teve a menor quantidade de pteridófitas. Nas três resoluções, as pteridófitas representaram um percentual mínimo das espécies, evidenciando a pequena importância dada a elas na elaboração dessas normas. Isso vale para outras normas aqui não avaliadas, como as resoluções de restinga do Paraná (447/2011), Rio Grande do Sul (441/2011) e de São Paulo (23/1996), e de florestas (02/1994, 33/1994 e $17 / 1994$, respectivamente) para os mesmos estados.

Grande parte dos táxons da resolução 261/1999 é de fato bom ou razoável indicador. Das 18 outras espécies aqui avaliadas como potenciais, cinco parecem boas indicadoras (Lomariocycas schomburgkii, Neoblechnum brasiliense, Pleopeltis hirsutissima, Pleopeltis pleopeltifolia e Serpocaulon latipes) e a maioria das outras necessita de novos estudos. Essas cinco espécies poderão em próxima resolução ser acrescentadas como indicadoras de restinga herbácea e/ou subarbustiva (a primeira), de estágios médio e avançado de restinga arbórea (a segunda) e de vegetação primária e estágio avançado de restinga arbórea (as três últimas); duas estão incluídas nas resoluções de restinga para o Paraná (447/2011) e/ou para o Rio Grande do Sul (441/2011), nos mesmos estágios: P. hirsutissima para ambos e $S$. latipes para o Paraná. Na resolução de restinga (23/1996) de São Paulo, também há gêneros citados como indicadores sem nomear as espécies (tais como Lycopodium spp. e Polypodium spp.), ao passo que nas resoluções do Paraná e Rio Grande do Sul isso não acontece.

Na resolução 423/2010, apenas duas espécies foram consideradas boas indicadoras, e foram encontradas menos informações sobre os táxons nela citados, pois são poucos os trabalhos com campos de altitude que salientam aspectos ecológicos das pteridófitas. As duas espécies de Gleicheniaceae foram problemáticas, uma por não existir e a outra por ser muito rara ou inexistente nessa formação. Há certa inconsistência taxonômica nessa resolução, dado que nomes de espécies nela citadas parecem nunca terem sido publicados.

A única pteridófita adotada na resolução 04/1994 foi aceita como boa indicadora, apesar dos poucos registros de coletas para uma das formações dessa resolução. $P$. esculentum subsp. arachnoideum foi ainda a única presente nas três resoluções, sendo aqui julgada boa indicadora do estágio inicial de regeneração de todas estas formações.

Durante essa revisão, percebeu-se a falta de informações ecológicas nas coletas das espécies avaliadas, tais como frequência, abundância, habitat, bem como ausência de coordenadas geográficas, altitude, condições de luminosidade e umidade, estágio sucessional, etc, com cerca de metade das coletas sem qualquer informação deste tipo. Destaca-se ainda a baixa quantidade de estudos ecológicos com pteridófitas nessas formações, e também há poucos trabalhos com as vegetações secundárias delas. Assim, os dados científicos disponíveis para as análises aqui expostas são limitados, o que também deixa pouco conhecido o comportamento ecológico de tantas espécies, mesmo que a ecologia forneça informações indispensáveis ao manejo de áreas conservadas e à recuperação de áreas degradadas, para o futuro das quais a legislação ambiental é tão decisiva.

Por outro lado, também é insuficiente a atenção científica dada a esta legislação, apesar da sua enorme importância prática e da diversidade das questões políticas nela envolvidas. As pressões sociais e os interesses econômicos interferem diretamente nos objetivos e na qualidade das normas que regulam o uso de áreas para empreendimentos comerciais, industriais ou residenciais, mas os técnicos do setor ambiental precisam também assumir a necessidade de conservação da biodiversidade como aspecto obrigatório nas tentativas de integrar ou harmonizar interesses políticos tão diversos. Assim, deve-se tentar aproximar e aperfeiçoar os campos da ciência e política, para que tenhamos resoluções mais corretas e efetivas, mais bem compreendidas e empregadas pelos seus usuários e que permitam a conservação de parte significativa das áreas naturais restantes.

\section{Conclusões}

Pouco mais de uma dezena de pteridófitas foram tratadas como indicadores nas resoluções aqui analisadas, porém se percebe a importância secundária do grupo em tais resoluções. Há várias incoerências nessas normas, como maior quantidade de espécies de pteridófitas indicadoras em formações nas quais elas não são tão importantes (restinga e campos), e uma única espécie incluída onde são muito destacadas (florestas), assim como a adoção de táxons inexistentes ou problemáticos. Diversos táxons apontados como indicadores não parecem bons para tal finalidade. Portanto, é necessário revisar essas resoluções (principalmente inserindo mais espécies de pteridófitas indicadoras na resolução de florestas), objetivando torná-las mais informativas e adequadas.

\section{Agradecimentos}

À Tania Tarabini Castellani e à Maria Leonor D'El Rei Souza, por críticas, sugestões e comentários muito úteis a uma versão inicial deste artigo, e aos revisores 
anônimos, que contribuíram para melhorar esta versão final.

\section{Literatura citada}

Andrade, B.O., Koch, C., Boldrini, I.I., Vélez-Martin, E., Hasenack, H., Hermann, J.M., Kollmann, J., Pillar, V.D. \& Overbeck, G.E. 2015. Grassland degradation and restoration: a conceptual framework of stages and thresholds illustrated by southern Brazilian grasslands. Natureza e Conservação 13: 95-104.

Athayde-Filho, F.P. \& Windisch, P.G. 2006. Florística e aspectos ecológicos das pteridófitas em uma floresta de Restinga no estado do Rio Grande do Sul, Brasil. Iheringia, Série Botânica 61: 63-71.

Behar, L. \& Viégas, G.M.F. 1992. Pteridophyta da restinga do Parque Estadual de Setiba, Espírito Santo. Boletim do Museu de Biologia Mello Leitão 1: 39-59.

Bresolin, A. 1979. Flora da restinga da Ilha de Santa Catarina. Insula 10: 1-54.

Campestrini, S. 2014. Aspectos florísticos, parâmetros fitossociológicos e ecológicos nos Campos de Palmas, SC/PR, Brasil. Dissertação de Mestrado, Universidade Federal de Santa Catarina, Florianópolis.

Daniel, R.B. 2006. Florística e fitossociologia da restinga herbáceo-arbustiva do Morro dos Conventos, Araranguá, SC. Dissertação de mestrado, Universidade do Extremo Sul Catarinense, Criciúma.

Danilevicz, E., Janke, H., Pankowski, L.H.S. 1990. Florística e estrutura da comunidade herbácea e arbustiva da Praia do Ferrugem, Garopaba, SC. Acta Botanica Brasilica 4: 21-34.

Della, A.P. 2016. Pteridófitas como indicadores ecológicos: revisão geral e aplicações em Santa Catarina. Trabalho de Conclusão de Curso, Universidade Federal de Santa Catarina, Florianópolis.

Gasper, A.L., Salino, A. 2015. Samambaias e licófitas de Santa Catarina: composição, riqueza e espécies ameaçadas. Iheringia, Série Botânica 70: 321-342.

Gomes, F.S., Guedes, M.L.S. 2014. Flora vascular e formas de vida das formações de restinga do litoral norte da Bahia, Brasil. Acta Biológica Catarinense 1: 22-43.

Gomes, M.A.M. 2009. Caracterização da vegetação de campos de altitude em unidades de paisagem na região do Campo dos Padres, Bom Retiro/Urubici, SC. Dissertação de mestrado, Universidade Federal de Santa Catarina, Florianópolis.

Gonzatti, F. 2015. Florística, fitogeografia e conservação das samambaias e licófitas da Região planície costeira do Rio Grande do Sul, Brasil. Dissertação de Mestrado, Universidade Federal do Rio Grande do Sul, Porto Alegre.

Gonzatti, F., Valduga, E., Wasum, R.A. \& Scur, L., 2014. Florística e aspectos ecológicos de samambaias e licófitas em um parque urbano do Rio Grande do Sul, Brasil. Revista Brasileira de Biociências 12: 90-97.
Guimarães, T.B. 2006. Florística e fenologia reprodutiva de plantas vasculares na restinga do Parque Municipal das Dunas da Lagoa de Conceição, Florianópolis, SC. Dissertação de Mestrado, Universidade Federal de Santa Catarina, Florianópolis.

Klein, A.S., Citadini-Zanette, V. \& Santos, R. 2007. Florística e estrutura comunitária de restinga herbácea no município de Araranguá, Santa Catarina..Biotemas 20: $15-26$.

Korte, A., Gasper, A.L., Kruger, A. \& Sevegnani, L. 2013. Composição florística e estrutura das restingas em Santa Catarina. In: A.C. Vibrans, L. Sevegnani, A.L. Gasper \& D.V. Lingner (eds.). Inventário florístico floresal de Santa Catarina, v. IV, Floresta Ombrófila Densa. Edifurb, Blumenau, pp. 285-309.

Magalhães, T.L., Lopes, R. \& Mantovani, A. 2013. Levantamento florístico em três áreas úmidas (banhados) no Planalto de Santa Catarina, sul do Brasil. Revista Brasileira de Biociências 11: 269-279.

Mania, L.F. \& Monteiro, R. 2010. Florística e ecologia de epífitas vasculares em um fragmento de floresta de restinga, Ubatuba, SP, Brasil. Rodriguésia 61: 705-713.

Maraschin-Silva, F., Scherer, A. \& Baptista, L.R.M. 2009. Diversidade e estrutura do componente herbáceosubarbustivo em vegetação secundária de Floresta Atlântica no sul do Brasil. Revista Brasileira de Biociências 7: 53-65.

Mauhs, J. 2002. Fitossociologia e regeneração natural de um fragmento de Floresta Ombrófila Mista exposto a perturbações antrópicas. Dissertação de Mestrado, Universidade do Vale do Rio dos Sinos, São Leopoldo.

Menezes-Silva, S. 1998. As formações vegetais da planície litorânea da Ilha do Mel, Paraná, Brasil: composição florística e principais características estruturais. Tese de doutorado, Universidade Estadual de Campinas, Campinas.

Mocochinski, A.Y. 2006. Campos de Altitude na Serra do Mar Paranaense: aspectos florísticos e estruturais. Dissertação de Mestrado, Universidade Federal do Paraná, Curitiba.

Nóbrega, G.A., Eisenlohr, P.V., Paciencia, M.L.B., Prado, J. \& Aidar, M.P.M. 2011. A composição florística e a diversidade de pteridófitas diferem entre a floresta de restinga e a floresta ombrófila densa das terras baixas do Núcleo Picinguaba/PESM, Ubatuba/ SP? Biota Neotropica 11: 153-164.

Øllgaard, B. \& Windisch, P. 2016. Lycopodiaceae in Brazil. Conspectus of the family II. The genera Lycopodiella, Palhinhaea, and Pseudolycopodiella. Rodriguésia 67: 691-719.

Paciencia, M.L.B. 2008. Diversidade de pteridófitas em gradientes de altitude na Mata Atlântica do estado do Paraná, Brasil. Tese de doutorado, Universidade de São Paulo, São Paulo. 
Resolução Conama n 2. 1994. Diário Oficial da União, 28-III-1994, n. 59, Seção 1, pp. 4513-4514.

Resolução Conama n 4. 1994. Diário Oficial da União, 17-VII-1994, n. 114, Seção 1, pp. 8877-8878.

Resolução Conama n 33. 1994. Diário Oficial da União, 30-VII-1994, n. 248, Seção 1, pp. 21351-21353.

Resolução Conama n 261. 1999. Diário Oficial da União, 2-VIII-1999, n. 146, Seção 1, pp. 29-30.

Resolução Conama n 423. 2010. Diário Oficial da União, 13-IV-2010, n. 69, Seção 1, pp. 55-57.

Resolução Conama n ${ }^{\circ}$ 441. 2011. Diário Oficial da União, 3-I-2012, n. 2, Seção 1, pp. 124-126.

Resolução Conama n 447. 2011. Diário Oficial da União, 3-I-2012, n. 2, Seção 1, pp. 130-132.

Sampaio, M.B. \& Guarino, E.S.G. 2007. Efeitos do pastoreio de bovinos na estrutura populacional de plantas em fragmentos de Floresta Ombrófila Mista. Revista Árvore 31: 1035-1046.

Santos, M.G., Sylvestre, L.S. \& Araujo, D.S.D. 2004. Análise florística das pteridófitas do Parque Nacional da Restinga de Jurubatiba, Rio de Janeiro, Brasil. Acta Botanica Brasilica 18: 271-280.

Sehnem, A. 1968a. Aspleniáceas. In: R. Reitz (ed.). Flora Ilustrada Catarinense. Herbário Barbosa Rodrigues, Itajaí.

Sehnem, A. 1968b. Blecnáceas. In: R. Reitz (ed.). Flora Ilustrada Catarinense. Herbário Barbosa Rodrigues, Itajaí.

Sehnem, A. 1970a. Gleiqueniáceas. In: R. Reitz (ed.). Flora Ilustrada Catarinense. Herbário Barbosa Rodrigues, Itajaí.

Sehnem, A. 1970b. Polipodiáceas. In: R. Reitz (ed.). Flora Ilustrada Catarinense. Herbário Barbosa Rodrigues, Itajaí.

Sehnem, A. 1972. Pteridáceas. In: R. Reitz (ed.). Flora Ilustrada Catarinense. Herbário Barbosa Rodrigues, Itajaí.

Sehnem, A. 1974. Esquizeáceas. In: R. Reitz (ed.). Flora Ilustrada Catarinense. Herbário Barbosa Rodrigues, Itajaí.
Sehnem, A. 1978. Ciateáceas. In: R. Reitz (ed.). Flora Ilustrada Catarinense. Herbário Barbosa Rodrigues, Itajaí.

Sehnem, A. 1979. Salviniáceas. In: R. Reitz (ed.). Flora Ilustrada Catarinense. Herbário Barbosa Rodrigues, Itajaí.

Silva, V.L., Mehltreter, K. \& Schmitt, J.L. 2018. Ferns as potential ecological indicators of edge effects in two types of Mexican forests. Ecological Indicators 93: 669-676.

Simão, C. 2008. Caracterização florística e espectro biológico de refúgios vegetacionais altomontanos no Morro Anhangava, Parque Estadual Serra da Baitaca, Paraná. Dissertação de Mestrado, Universidade Federal do Paraná, Curitiba.

Sonehara, J.S. 2005. Aspectos florísticos e fitossociológicos de um trecho de vegetação de restinga no Parque Estadual do Rio da Onça - Matinhos. Dissertação de Mestrado, Universidade Federal do Paraná, Curitiba.

Souza, M.L.D.R., Falkenberg, D.B., Amaral, L.G., Fronza, M., Araujo, A.C. \& Sá, M.R. 1991. Vegetação do Pontal da Daniela, Florianópolis, SC, Brasil. I. Levantamento florístico e mapa fitogeográfico. Insula 21: 87-117.

SpeciesLink. 2019. Disponível em: http://www.splink.org. $\mathrm{br} /$ index?lang=pt.

Tabarelli, M. \& Mantovani, W. 1999. A regeneração de uma floresta tropical montana após corte e queima (São Paulo - Brasil). Revista Brasileira de Biologia 59: 239-250.

Turnhout, E., Hisschemöller, M. \& Eijsackers, H. 2007. Ecological indicators: between the two fires of science and policy. Ecological Indicators 7: 215-228.

Záchia, R.A. \& Waechter, J.L. 2011. Diferenciação espacial de comunidades herbáceo-arbustivas em florestas costeiras do Parque Nacional da Lagoa do Peixe, Rio Grande do Sul. Pesquisas, Série Botânica 62: 211-238.

Zanin, A., Longhi-Wagner, H.M., Souza, M.L.D.R. \& Rieper, M. 2009. Fitofisionomia das formações campestres do Campo dos Padres, Santa Catarina, Brasil. Insula 38: 42-57. 